\title{
Digital Nudging for More Ecological Supermarket Purchases
}

\author{
Wim Fechner \\ wimfechner@icloud.com \\ Radboud University \\ Institute for Computing and Information Sciences \\ Nijmegen, The Netherlands
}

\begin{abstract}
Most western countries are currently using more of the earth's resources than they produce, exhausting the earth and causing permanent damage. This study aims to determine how people can be nudged towards more ecological consumer behavior when using web supermarkets. An experimental website and a survey are created to explore consumers' willingness to try more ecological alternatives. The results confirm that digital nudges - more specifically, the decoy effect and the middle-option bias - can guide participants towards more ecological meat alternatives, as compared to a website without nudges. We also investigated the influence of price tags by also including scenarios without price information with and without nudging. Without price information, our participants steered towards more sustainable (organic) alternatives even without nudges; the effect of the nudges was limited in these situations, without price tags, only the middle-option nudge managed to convince participants to take the even more ecological, vegetarian alternative. The combined results lead to the belief that the decision to not opt for organic meat is primarily motivated by price, whereas the decision to go vegetarian (arguably even more sustainable) is not motivated by price, but rather by the effect of the nudges.
\end{abstract}

\section{CCS CONCEPTS}

- Human-centered computing $\rightarrow$ Empirical studies in $\mathrm{HCI}$; Applied computing $\rightarrow$ Online shopping.

\section{KEYWORDS}

Digital nudges, ecological purchase behavior, web supermarket

\section{ACM Reference Format:}

Wim Fechner and Eelco Herder. 2021. Digital Nudging for More Ecological Supermarket Purchases. In Adjunct Proceedings of the 29th ACM Conference on User Modeling, Adaptation and Personalization (UMAP '21 Adjunct), June 21-25, 2021, Utrecht, Netherlands. ACM, New York, NY, USA, 9 pages. https: //doi.org/10.1145/3450614.3464620

\footnotetext{
Permission to make digital or hard copies of all or part of this work for personal or classroom use is granted without fee provided that copies are not made or distributed for profit or commercial advantage and that copies bear this notice and the full citation on the first page. Copyrights for components of this work owned by others than ACM must be honored. Abstracting with credit is permitted. To copy otherwise, or republish, to post on servers or to redistribute to lists, requires prior specific permission and/or a fee. Request permissions from permissions@acm.org.

UMAP '21 Adjunct, June 21-25, 2021, Utrecht, Netherlands

(c) 2021 Association for Computing Machinery.

ACM ISBN 978-1-4503-8367-7/21/06 . \$ \$15.00

https://doi.org/10.1145/3450614.3464620
}

\author{
Eelco Herder \\ eelcoherder@acm.org \\ Radboud University \\ Institute for Computing and Information Sciences \\ Nijmegen, The Netherlands
}

\section{INTRODUCTION}

The market for online grocery shopping has shown a rapid increase over the last few years: the number of consumers that purchased food items online has nearly doubled between 2015 and 2017 (from 15\% to 29\%) [3]. This increase is especially apparent in the Netherlands: the percentage of online supermarket consumers in the Netherlands is $29 \%$, which is far higher than the average of the EU (14\%) [3] and US (10\%) [14]. An article published in 2020 by Nielsen [13] even predicts that the total value of grocery ecommerce will increase from $€ 1$ billion in 2018 to an estimated $€ 1.8$ billion by the end of 2020 .

Web supermarkets are online, website-based grocery stores. On web supermarkets, consumers can purchase their 'daily groceries', the e-commerce way. In essence, web supermarkets are a form of e-commerce as we know it, but they aim to take on a new section of the e-commerce market by facilitating a - for e-commerce - new section of products, and - a for supermarkets - new platform to sell on.

The user interface of web supermarkets may be one-size-fits-all, or they may be personalized. The background knowledge for adaptation decisions is usually derived from implicit interaction cues [15]. For instance, they can make the interaction more satisfactory for the user by making it more useful (find more relevant products) or efficient (find related products faster) by suggesting appropriate elements.

Making use of various techniques, such as the specific placement of buttons, companies can guide or steer consumer behavior in a particular direction [11]. This guiding of people's behavior in the context of UI design elements is a concept called Digital Nudging (DN) [23]. For instance, changing the default option from opt-in to opt-out already affects the behavior outcome [23].

Web supermarkets could consequently be ideal environments for countering the process of exhausting the earth's resources, because they can utilize $\mathrm{DN}$ to recommend ecological items. When consumers can reduce their ecological footprint by buying products more consciously and based on their environmental footprint, web supermarkets could use this presumption as an opportunity to make consumers consider buying more ecological items.

Aspects of this paper aim to contribute to the research by providing examples of what factors are usable in applying DN and which are not, in the context of web supermarkets. It also adds to the research on DN by providing insight into DN concepts that are applied to web supermarkets.

In this paper, we define the research question: How can digital systems nudge customers of web supermarkets into buying more eco friendly meat products/alternatives? To answer this, we investigate 
to what extent nudging techniques can be used in web supermarkets in order to encourage customers to choose for more ecological products instead of regular, cheaper and less sustainable products. We experiment with two different nudging techniques and, in addition, investigate the effect of the presence of absence of price labels on customer choices.

The remainder of this paper is as follows. In the next section, we discuss various strands of related work on ecological buying behavior, advertising and digital nudging. In Section 3 we explain the nudges, the website design and experimental setup. We then continue with the various results, followed by a discussion and conclusion.

\section{BACKGROUND AND RELATED WORK}

The web supermarkets, as covered in this study, find their roots in the combination of both traditional 'brick and mortar' supermarkets and the field of e-commerce. From the perspective of supermarkets, a transition to the web concerns primarily the digitization of a supermarket, meaning that the products do not differ as such, but the shopping environment is relatively new to the field. From the perspective of existing e-commerce, a transition to a web supermarket concerns the selling of a product kind that is relatively new to the field of e-commerce, in an otherwise well-known and understood digital context.

Although the literature on digital nudging already indicated how the decoy effect and the middle-option bias could convince consumers to divert consumer behavior towards buying intended products, the literature still misses specific results on web supermarkets for these particular nudges. The results of the 'web supermarket' experiment indicate that web supermarkets can also use digital nudges such as the decoy effect and the middle-option bias to guide consumers towards more ecological meat (or meat alternative) purchase behavior. These results are intended to close the literature gap and provide yet another environment and instance of successful digital nudge application.

\subsection{Stimulating ecological buying behavior}

To be able to include nudges that can guide consumers into a more ecological direction, products need to be classified based on their ecological footprint, which is an aggregated measure of the demand on nature's capital ${ }^{1}$. To determine the extent to which supermarket purchases contribute to the harmful footprint, one needs to consider consumers' purchase decisions. The consumer purchase decisions include what product categories consumers buy, if they consider the ecological variants of the particular product categories, and the purchase frequency.

When consumers aim to shop ecologically, they should consider what product they buy, and buy low footprint items as much as they can. Ecological meat, for instance, brings a variety of benefits for the environment. But in terms of the ecological footprint, not opting for meat altogether is arguably the best option [9].

To help consumers recognize more ecological variants of the products they are interested in, food labels may help. The inclusion of a label on a product can, for instance, have the intention to communicate a certification to the customer that a certain level of

\footnotetext{
${ }^{1}$ https://www.footprintnetwork.org/our-work/ecological-footprint/
}

sustainability has been met $^{2}$. However, having a label attached to a food product does not automatically make it sustainable, and there are many differences between food labels in the way they measure and set demands for products. Understanding the challenges that are paired with using food labels should help when trying to get customers to choose for a particular product variant in a web supermarket - by using a credible food label instance that aims to make a statement about the ecological footprint of the particular product.

\subsection{Advertising mechanisms of traditional supermarkets}

Gidlöf et al. [8] conducted research on how visual attention and choice are affected by consumer preferences and properties of the supermarket shelves. Supermarkets apply various advertising techniques to influence consumers, such as visual cues. The techniques are based on psychological persuasion concepts.

Advertising techniques usually aim to increase unplanned product purchases. Advertising techniques can be divided into external factors and internal factors. External factors comprise visual salience, the number of facings, and the placement of each product. Internal factors comprise several goals and interests related to the products and their attributes, which implies that purchase decisions - like most decisions - are based on visual stimulation [8]. These external factors or visual cues shape the basis of used persuasion techniques.

Gidlöf et al. [8] found that when it comes to purchases, visual attention was by far the most important predictor. The very act of looking longer or repeatedly at a package made it more likely that the product would be bought. Visual attention is thus crucial for understanding consumer behavior, although it cannot be captured by measurements of visual salience alone.

The broad application of the aforementioned classic techniques indicates that utilizing them is a feasible practice - whether it is meant to convert more of a particular product, alter purchase behavior, or to change an attitude towards something. When designing advertising techniques for web supermarkets, advertisers can consider the more classic supermarket advertising techniques additional to the modern personalization inspired advertising practices used in e-commerce, such as recommender systems.

\subsection{Digital nudging through interface design}

In digital environments, people have to make choices based on the available information or content, as presented in information systems [17]. What is chosen largely depends on how information is presented [11], because people have cognitive limitations, and therefore their rationality is bounded [19]. Heuristics ('rules of thumb') and biases typically drive their decision making [21].

Schneider et al. [17] describe that digital nudging works particularly well by either modifying what is presented - the content of a choice $[6,22]$ - or how it is presented - the visualization of a choice - by changing the design of a user interface [11]. The study then proceeds to elaborate on the theory by giving a number of instances on how the digital nudges can be applied. Among those instances are the decoy effect and the middle-option bias, which became the

\footnotetext{
${ }^{2}$ https://www.voedingscentrum.nl/encyclopedie/keurmerken.aspx
} 
nudges that are applied in this paper, both through interface design convenience and expected applicability in the research context. We will discuss both effects later on in this paper.

\subsection{Pro-environmental nudging}

According to Byerly et al. [2], evidence suggests that social influence and simple adjustments to decision settings can influence pro-environmental decisions. In the research, 160 experimental interventions are reviewed. These interventions attempt to alter behavior in six domains in which decisions have major environmental impacts, such as family planning, land management, and meat consumption. Their findings include that information about social norms and changes to the decision context can encourage pro-environmental behavior, especially in relation to water conservation, sustainable land management, and reduced meat consumption. These findings lead to the belief that nudging towards ecological outcomes may also have similar feasible outcomes for the environment when applied in the context of web supermarkets and e-commerce.

\subsection{Nudging towards sustainable/healthy consumption in an online supermarket}

Demarque et al. [5] researched how descriptive norms could be used to promote a minority pro-environmental behavior in an online shopping environment. The product selection consisted of 84 products from a French grocery chain, of which 24 products had an ecological label. Nudging was achieved through the use of ecolabels, which are "social norm" based. The research showed that when participants were presented with strong formulations of descriptive norms, they purchased more eco-labeled products than participants from the control group. Those findings suggest that green consumption can be truthfully described in such ways that sustainable consumption in an online shopping environment can be stimulated.

Adaji et al. [1] have taken a different approach in convincing online grocery shoppers to make better food choices. The study focused on making consumers buy healthier products, by giving them tailored messages as part of a game. The game simulates supermarkets aisles that consumers can explore. The healthier the products that the users select, the more points they can earn. Adaji's research showed that players change their behaviors effectively when reading messages that were tailored to them. After people filled out questions regarding their personality and their previous shopping behavior, they could be characterized. For instance, people who like authority were provided with a message that would be from the Ministry of Health, whereas people who value their friends opinion more, were presented with recommendations based on their friends choices. The study found that the targeted messages were twice as effective as more traditional messages about healthy eating.

\subsection{Effects of nudging and pricing on healthy food purchasing behavior in a virtual supermarket}

The study conducted by Hoenink et al. [10] aimed to capture the effect of both nudging and pricing on healthy food purchasing behavior in a virtual supermarket setting. A virtual supermarket is a three-dimensional, web-based supermarket that aims to simulate a real-life shopping experience by imitating a typical (Dutch) supermarket [10]. The study aimed at using both pricing and nudging to increase healthy food purchases. Moreover, this study examined the potential differential effect by socio-economic position, which was assessed by using either education or income as a proxy.

The supermarket used had 19\% (221/1175) of healthy products. Whether something was healthier was established in terms of being fresh, unprocessed or lightly processed foods. The kind of nudges that were used were salience nudges, which are nudges that draw an individual's attention towards a particular option. Wilson et al. [24] describe them as nudges that invoke reactions that will be elicited primarily through emotional associations in response to the nudge.

The researchers used a mixed randomized experimental study design consisting of five study conditions (within-subject design) and three study arms (between-subject design). Participants were randomized into one of the three study arms (25\% price increases, $25 \%$ price discounts, or $25 \%$ price increases and discounts) and within these arms exposed to five study conditions (control, nudging, pricing, price salience, and price salience with nudging). Nudges and non-salient price strategies alone had limited effects. Also, salient price increases alone or salient price discounts alone did not increase the percentage of healthy purchases, while the combined salient price increases and discounts increased the percentage of healthy food purchases. Moreover, nudging and/or pricing strategies do not seem to widen SEP inequalities

\subsection{Analysing the Decoy Effect on Online Product Purchasing Preference}

This research conducted by [18] analyses whether the decoy effect exists in Indonesia's digital marketplace, and what effect the customers' reviews have on it, across smaller and bigger population sizes. The data for this study is collected through online surveys, and their experiment aimed to replicate online shopping choice sets for a trash bin.

It uses four treatment choice sets. Treatment 1 is used to test if the decoy effect has an effect in the digital market, it uses a negative decoy. Treatment 2 aims to measure the effectiveness of a decoy nudge across smaller and bigger numbers of buyers, utilizing a positive decoy. Treatment 3 was used to measure the effectiveness of a decoy with positive or negative reviews by using a decoy minimum, while Treatment 4 uses a decoy maximum. Decoy minimum and maximum are used to indicate how many units of an item are sold, for a particular product.

The decision to use a trash bin in the experiment was deliberate. Compared to high involvement products such as a smartphone or television, which have a multitude of dimensions to consider a product for - such as screen resolution and brightness - a trash bin has mostly just the price and review rating as dimensions [7]. 
In the first treatment design, the target item is a car trash bin. The bin was being sold at Rp. 50.000,- (about $€ 2,90$ ), while competitor item is priced cheaper: Rp.33.000,- (about $€ 1,90$ ). The target item has a high review rating of 5 stars out of 5 and the competitor item has 4.5 stars. The target and competitor item have an almost similar number of products sold. The difference between the two is that the decoy in Treatment 4 has the most number of products sold, whereas the decoy in Treatment 3 has the least number of products sold.

In the second treatment design, the decoy was the same product as the competitor, but it was being sold in a different store with a slightly higher price than the competitor's product. It was designed to see whether there is a shift in Indonesian citizen science preference as a result of the decoy effect in the digital marketplace.

The results show that in the experiment, the decoy effect does exist in the digital marketplace used. In this experiment, online buyers can be influenced to change their preference towards low involvement products such as a car trash bin by introducing a decoy that is similar to the competitor but has negative reviews from previous buyers. The data also implies that a negative review can have a moderating effect on the respondent's decision-making process. Furthermore, the amount of buyers influences the strength of the decoy effect; where the smaller amount weakened it, the bigger amount strengthens it. Lastly, the data suggests that a decoy with negative reviews reduces the strength of its effect and vice versa.

\section{METHODOLOGY}

To test if consumers can be nudged towards more ecological purchasing behavior, two nudges have been designed. The design is structured following the cycle of DN design [17], a methodology that enables choice architects and alike to deliberately develop choice environments. To measure the effect that pricing has on purchase behavior and whether the absence of pricing influences the nudging, variants of the nudged websites without price tags are included as well. Additionally, the effect of adaptivity was also measured in the experiment using a pop-up notification. This element is excluded from this paper, because the result implications are not relevant in the context of this paper.

To test the nudges, an experiment is created in the form of a website, a 'web supermarket.' The experiment is combined with a survey, which aims to capture variables - such as prior shopping preferences - that may influence the data measured in the experiment. The survey first asks a number of questions and then directs the participant to the experiment, the web supermarket. In the experiment, participants are shown different versions of the experiment, utilizing $\mathrm{A} / \mathrm{B}$ testing. $\mathrm{A} / \mathrm{B}$ testing is a form of user experience testing that consists of a random experiment with two variants, $\mathrm{A}$ and $B$ [12]. After the execution of the experiment, in which the seven different versions are tested, further survey questions follow about prior shopping behavior and opinions. For instance, when a consumer was already buying eco-friendly products in their daily life, they may perhaps be more inclined to buy ecological meat in the control variable (version A: includes pricing and does not nudge) of the web supermarket than someone who does not.
Note that the footprint values for the products used have not been assessed, they are assigned arbitrarily.

\subsection{Decoy Effect nudge}

With the decoy effect, a selection of three products is introduced. The first product in the nudging selection is a regular meat product. The second option is the decoy product. It is an organic meat option, better than the regular (first) option, but not as good as the best (third) option. The decoy functions as a product that is not primarily meant to be sold, but is mainly acting as a decoy - diverting consumers' attention towards the third, most expensive, and most ecological option. The third option is called the 'key product', which is dominating the decoy, and it is placed within the proximity of the decoy product. Moreover, the decoy product is usually priced close to the key product, only costing slightly less than the key product. The key product has the lowest footprint - which means in the context of this study - that it has extra 'features.' It is a vegetarian option.

Designing the decoy effect nudge on the web supermarket experiment is done by making a separate product page. When a user chooses the unsustainable, regular minced chicken schnitzel, the page shows the two other products below it. The page also has a message displayed on the top of the page in red: "The product selected by you has some nice alternatives, why don't you check them out below?" The nudge will only be shown when a user selects the unsustainable option. In other cases, the user will not be shown any nudge. Of these products, the middle option is the decoy, and the last option is the product a user should choose. The products feature both pricing and footprint information:

- Unsustainable option: $€ 2.49$, ecological footprint: $100 \%$

- Organic option: $€ 3.49$, ecological footprint: $85 \%$ (decoy product)

- Vegetarian option: $€ 3.74$, ecological footprint: $45 \%$ (key product)

\subsection{Middle-option bias nudge}

The middle-option bias nudge also makes use of the three-product selection, but it works slightly differently. The first difference with the decoy effect nudge is that it does not make use of a distinct decoy and key product. Therefore, there is no deliberate pricing strategy, and the products are not priced differently than in website versions without nudges. The second difference is that in this case, the user is tempted to opt for the middle option and not the third option. To make this middle option more significant, the border is colored green, whereas the other options are colored grey

A visual demonstration of how the decoy and middle-option bias nudges are implemented can be seen in Figure 1. When a user chooses the unsustainable, regular minced chicken schnitzel, the middle-option will show the same initial setup that the decoy effect nudge does - it shows the product alternatives and the message at the top of the page, which asks users to consider the alternatives. The products feature both pricing and footprint information:

- Unsustainable option: $€ 2.49$, ecological footprint: $100 \%$

- Vegetarian option: $€ 2.69$, ecological footprint: $45 \%$ (middle option)

- Organic option: €3.59, ecological footprint: $85 \%$ 


\subsection{Pricing strategies}

The two nudges that are incorporated into the website are both expected to increase participants' interest into the vegetarian meat alternative. Which particular nudge would be more effective is likely to depend on multiple factors, among which the particular implementation of the nudges. Therefore, neither nudge was expected to perform better than the other during the design of the experiment.

Lastly, the website includes both variants with and without prices. Price is the most important reason to not purchase organic food, mainly because of the rather large price difference between organic and conventional food products [4]. If the price is excluded from the meat/alternative decision process, it cannot influence the purchase decision. Therefore, it was expected that results with regard to what meat product or alternative a participant will choose, differs in an environment without price labels.

\subsection{Website design}

An experimental website has been set up to measure the possible effectiveness of the chosen nudges. This website represents a simple web supermarket where participants can buy three kinds of products: potatoes, vegetables, and meat or meat substitutes. Participants were asked to purchase one of each these three product kinds, but it was not specified for how long participants had to use the website.

The website contains only the core functionality that is necessary for the experiment and consists of four main pages, as indicated by the menu bar. The first page is the homepage - or landing page on which users arrive when they follow the given URL. It features the necessary headers to suggest that it is a real web supermarket and a recently added products section. The second page is called 'Products' and features all the products that the site contains. The third page is called 'Research' and provides the research context of the website. The last included page is 'Survey'. Should participants have accidentally closed the survey page, then they can return and retake the initial survey via this route.

Upon adding a product to the cart, the user is directed to the cart page, which gives an overview of all the products in the cart. In our study, we compared all nudge variations (no nudges, decoy nudge and middle-option nudge) in two conditions (with and without price information), taking the condition without nudges and with price information as a baseline.

Users are asked to enter their name, so that the shopping result can be matched with the survey result of the same participant. The users are also notified that their names will be anonymized. Placing the order directs the user to the last page of the sequence, the 'place order' page, which thanks the user for their input - concluding the experiment part of the research.

\subsection{Survey design}

The survey aims to capture factors, such as prior shopping preferences, that may influence the data measured in the experiment. The survey introduces the experiment and then directs the participant to the experiment, the web supermarket.

The experiment proceeds to ask the participant to pick three products; potatoes, vegetables and a meat product or substitute.
For the sake of the experiment, only the meat and meat substitute products are relevant. Note that an essential design element of this page is the ecological footprint, which is shown next to the price. The display of footprint is meant to add perceived value to a more ecological product, signifying the added value of the alternatively suggested products.

After the execution of the experiment, further survey questions follow about prior shopping behavior and opinions. For instance, when a consumer was already buying eco-friendly products in their daily life, they may perhaps be more inclined to buy ecological meat in the control variable version A of the web supermarket than someone who does not. The survey structure and questions asked are as follows:

(1) Introduction to the survey:

An explanation about the experiment: "You are now requested to go to the web supermarket to pick products to create a simple meal with. Please add to your cart, three product of preference (remember these three well): Potatoes, Vegetables, Meat or equivalent. You can do this by going to the products page, selecting the products you want and by adding them to your cart. Once you have gathered the products in your cart: Enter your name and click "save name". Now click "place order" ".

A link to the experiment website: "Now please go to the site"

A verification: "Did you finish your order on the site and enter your (nick)name?"

(2) Questions to classify participants:

What is your name? (note that you may enter a nickname, as long as you use it consistently throughout the experiment) What is your age (in years)?

What is your nationality?

What is your gender?

What is your highest completed level of education?

(3) Questions to assess prior behavior and set a baseline:

Are you a vegetarian / vegan?

When I shop for meat, I tend to go for the biological option. When I shop for meat, I tend to go for the vegetarian option.

When I shop for meat, I tend to go for the cheapest option. I feel that buying ecological meat products as opposed to regular meat products helps to reduce ecological footprint.

I would like to go for the more ecological meat option, but I am not willing to spend extra money on it.

I would like to go for the more ecological meat option, but I dislike the alternative products.

I am conscious about the ecological impact of buying meat products.

I feel that price is generally the most important factor when buying meat products or equivalents.

(4) The participant is thanked for their input.

In the survey, there are two different scales used to gather input on the opinion of participants towards questions. The first scale is a 5 point Likert Scale [16] to which people can answer only one of the five options: strongly disagree, disagree, neither agree nor disagree, agree, strongly disagree. This scale is used because it is a 


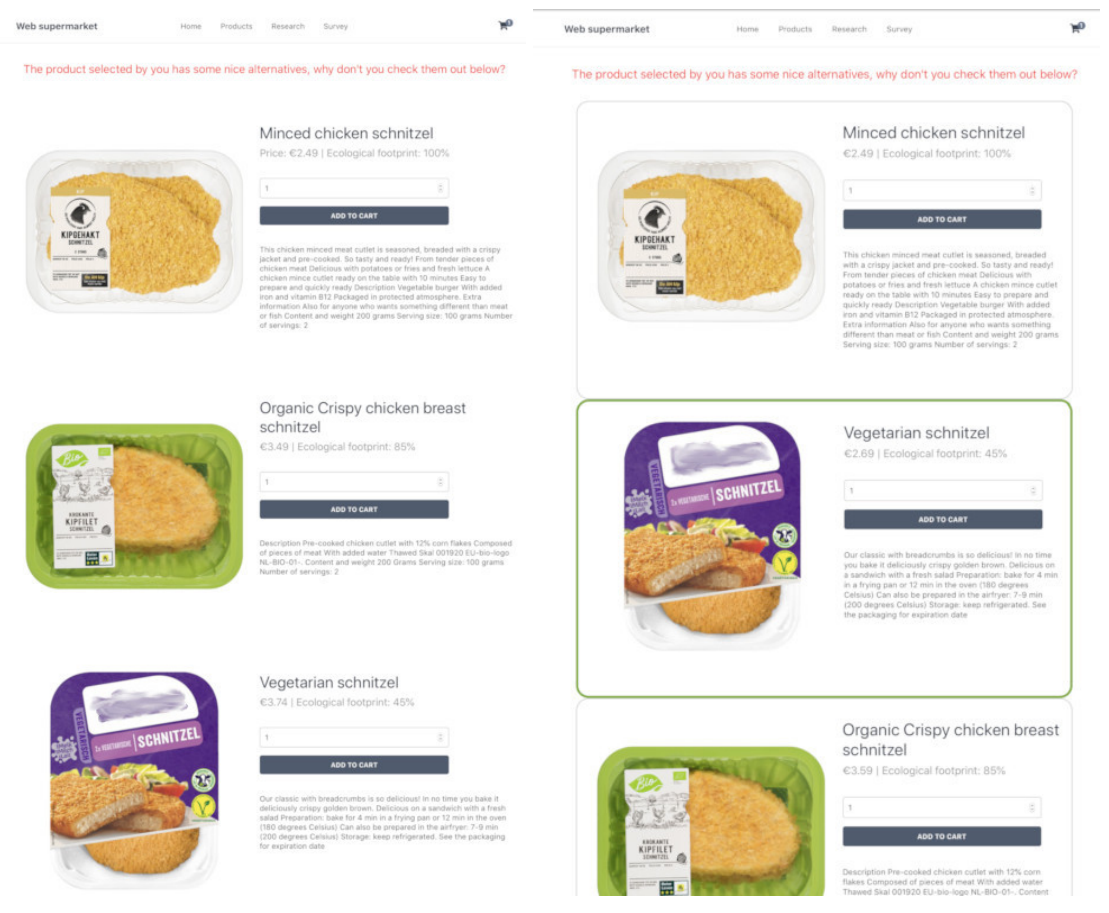

Figure 1: Decoy (left) and middle-option (right) bias nudges

universal method for collecting data, and it is easy to understand [20].

\subsection{Participants}

The survey has been sent to participants through various social media channels: Facebook, Whatsapp, and LinkedIn. This resulted in a convenience sample of 226 responses. The majority (73\%) of participants is aged between 18 and 29, and (79\%) is Dutch. $82 \%$ has completed at least a Bachelor's degree on either University or University of Applied Sciences level.

Survey entries that are not finished are excluded. The remainder consists of 204 usable entries. Still, not all entries are suitable for every analysis, because some participants did not fill out certain questions. In every separate analysis that is generated, it is shown how many usable results are included, denoted by $\mathrm{N}$.

\subsection{Collection and Analysis of results}

The experiment data was collected in two ways: from the experiment website and using the survey. The website captured the respondents' input by writing the respondent information to a file. Survey data was captured using typical survey software. Both data could only be accessed by the researcher. Both data entries could be identified as being from the same participant, and be linked to each other by matching the names/nicknames used. After matching the records, the data was anonymized.

Proceeding, Pearson's Chi-squared $\chi^{2}$ test and Fisher's Exact Test for Count Data are used to analyze the results. $\chi^{2}$ measures how the data expectations compare to actual observed data; determines

$\begin{array}{lllccc}\text { Version } & \text { Nudge } & \text { Price } & \text { Regular } & \text { Biological } & \text { Vegetarian } \\ \text { A } & \text { No } & \text { Yes } & 57 \% & 24 \% & 24 \% \\ \text { B } & \text { Decoy } & \text { Yes } & 20 \% & 27 \% & 53 \% \\ \text { C } & \text { Middle } & \text { Yes } & 30 \% & 20 \% & 50 \% \\ \text { D } & \text { No } & \text { No } & 27 \% & 45 \% & 27 \% \\ \text { E } & \text { Decoy } & \text { No } & 26 \% & 46 \% & 28 \% \\ \text { F } & \text { Middle } & \text { No } & 30 \% & 40 \% & 30 \%\end{array}$

Table 1: Experiment results summarized $(\mathrm{N}=170)$

whether there is an association between categorical variables ${ }^{3}$. The aim is to see whether there is a significant difference between the variables across various experiment versions. In some of the results, there are few individual cell sizes (around 10 observations), which is around the threshold. Whenever the $\chi^{2}$ test indicated that the approximation might be incorrect, Fisher's Exact Test for Count Data is used additionally. It is a test that can be preferable to the chisquared test because it is an exact test, opposed to the approximate estimate of $\chi^{2}$.

\section{RESULTS}

To give an overview of the website variants, Table 1 summarizes the different web site versions and the results of the experiment per version.

$\overline{{ }^{3} \text { https://libguides.library.kent.edu/SPSS/ChiSquare }}$ 


\subsection{Website experiment results}

First of all, we are interested in the impact of the decoy and middleoption nudges on the meat selection. As explained earlier, the nudges were intended to stimulate participants to choose for a more sustainable product - in our case, organic meat or a vegetarian meat alternative. Indeed, if the decoy nudge was present, the vegetarian alternative selection went up from $24 \%$ to $53 \%$ in version $\mathrm{B}$ compared to version $\mathrm{A}$ : the Chi-squared test for results of versions with and without the decoy nudge produce the following: $\chi^{2}(2, \mathrm{~N}=58)=9.32,(p<0.01)$. Moreover, the organic meat option was chosen slightly more frequent as well.

Similarly, in presence of the middle-option nudge, the vegetarian alternative went up from $24 \%$ to $50 \%$ in version C compared to version $\mathrm{A}$. The Chi-squared test for results of version with and without the middle-option bias nudge produce the following: $\chi^{2}$ $(3, \mathrm{~N}=48)=14.62,(p<0.01)$. The organic meat, however, was not selected more often than in the control group. When comparing the effects of both nudges, it becomes apparent that the middleoption nudge works differently than the decoy nudge and is less effective at doing so - the Fisher Exact test returned $(p<0.01)$ for a two-sided test.

We also presented versions without price information. As expected, without price information, the sales of organic meat increased slightly, even without nudge. As expected, both the decoy and middle-option nudges did not succeed in convincing participants to go vegetarian - as the decoy effects largely depend on the price.

Apart from the nudges, the presence or absence of price information was expected to have a significant effect on meat selection choices. Indeed, if price information was not present, organic meat preference went up from $24 \%$ to $45 \%$ in version D compared to version $\mathrm{A}-\chi^{2}(2, \mathrm{~N}=61)=6.05,(p<0.05)$, a weakly significant effect. By contrast, participants did not choose for the - arguably more sustainable - vegetarian option more often. Finally, as can be observed in Table 1, in the absence of price information, the effects of both the decoy and the middle-option nudge were hardly noticeable - statistical tests produced non-significant results. This is an expected result, since the nudges largely rely on pricing due to their design.

To summarize the results, both the decoy effect and middleoption bias nudge guide consumers towards more ecological meat alternatives. The decoy effect nudge is slightly more effective at nudging consumers towards the more ecological meat alternatives. However, neither of the nudges work as effectively without the inclusion of prices. Still, whenever price information is missing, the organic meat selection became the most popular, regardless of the presence of nudges.

\subsection{Survey results}

The survey was aimed to relate participants' self-stated attitude towards ecology and sustainability with their actual meat selection choices.

The first statement, "I feel that buying ecological meat products as opposed to regular meat products helps to reduce ecological footprint", was weakly related to the actual meat selection $\left(\right.$ Exact $\left.+\chi^{2}\right) / 2=$ $(p<0.05)$. This confirms the intuition that participants do opt for the ecological meat selection more frequently when feeling that buying ecological meat helps to reduce the ecological footprint. The same yields for the statement "I am conscious about the ecological impact of buying meat products".

By contrast and in line with our expectations, there was strong evidence that participants who agreed with the statement "When I shop for meat, I tend to go for the cheapest option" actually did opt for the cheapest option more frequently $\chi^{2}(10, \mathrm{~N}=146)=26.22$, $(p<0.01)$. However, this effect was not observed for the more generic statement "I feel that price is generally the most important factor when buying meat products or equivalents" $\chi^{2}(10, N=146)=$ 10.68, $(p>0.1)$.

Finally, unsurprisingly, we confirmed that participants who indicated to be vegetarian or vegan are more conscious about the ecological impact of meat products $\chi^{2}(4, \mathrm{~N}=146)=25.33,(p<0.001)$.

To summarize, the survey results confirmed that participants who feel that buying more ecological meat helps to reduce the ecological footprint, as well as those who feel conscious about the ecological footprint, indeed do opt for the more ecological meat more often. By contrast, price-conscious participants did not opt for the cheaper option more frequently - with the exception of those who explicitly indicated to always go for the cheapest option.

\section{DISCUSSION}

There is strong evidence that the decoy effect nudge is effective at guiding participants into opting for the vegetarian meat alternative. The results show that - in the context of web supermarkets - decoy effect nudges can be used to guide consumers towards a more ecological meat selection, while at the same time steering them away from less ecological regular meat products. The same trend is seen with the middle-option bias nudge. However, the decoy effect nudge managed to nudge slightly more participants towards the more ecological options.

It was expected that removing the pricing from the website would influence purchase behavior, and indeed there was weakly significant evidence to back this up: statistics showed that when price does not play a visible factor, organic meat becomes the most popular meat selection. There is evidence that meat purchases are indeed price bound, but the purchases are not as severely influenced by pricing as they are by nudging, and they show not to overrule the nudges.

Participants did feel that choosing organic meat does help reduce the ecological footprint (regardless of whether it does), and they also felt conscious about the impact of buying meat products. Overall, participants who agreed with this statement, did show more ecological purchase behavior.

In terms of recommendations, it could mean that using nudges can be slightly more effective to convince people who believe in the ecological argument than to convince the people who do not. Still, web supermarkets could target both sides of the population with their ecological nudges, whether the people believe in the effect or not.

\subsection{Limitations \& design choices}

The argument for the deliberate design choice to include both organic and vegetarian options as part of the nudges, is to give people 
the freedom to make the trade-off themselves - whether it is organic or vegetarian. It is the nudges' goal to guide people into opting for the most eco-friendly option, but any improvement over the regular meat option is arguably one in the right direction. Opting for the eco-friendly product would be more motivated by just improved animal welfare, whereas opting for the vegetarian product would be motivated by even further improved animal welfare and decreasing the ecological footprint.

According to the nudge theory, nudges need more elaborate testing and adjusting. In order to validate earlier findings, testing should be done throughout a long process that adjusts nudges and tries different angles to see how they can be applied most effectively.

Moreover, the experiment is limited to testing with 'virtual money' since participants have spent no actual money. Although participants are presented versions of the website with and without prices, they are not actually spending their own money. Therefore, it would be better to replicate this experiment in an environment where people do spend their own money to see if the results remain the same. Further research is needed to relate the experiment results in 'real-world' results.

Also, more time could be taken into designing a more extensive research environment with multiple meat selections and variants. More extensive research would include the possibility to analyze the relation between meat selection and other product selections, such as measuring whether ecological meat preference is paired with ecological vegetable preference. This remains a limitation, because it requires extensive website modifications that did not fit within the timeline of this study.

Further research could provide valuable insights into the relationship between ecological meat selection and ecological vegetable selections. Moreover, they could provide information on whether using a nudge to guide participants towards a more ecological meat selection successfully, could be the (indirect) reason that participants start to consider other ecological products as well.

Lastly, one notable remark to this research is that the survey itself does not include an open field for respondents to comment. A comment box would have been a useful addition but was initially not added. However, it was addressed by adding contact information in the website footer. The contact information provided participants with an e-mail link to which they can send questions or remarks. Although an open field to comment on the survey would have been useful, the website link was deemed sufficient.

\subsection{Design implications}

When web supermarkets consider implementing the two introduced nudges, they first need to consider their current user interface. Elaborate testing will be needed to ensure proper nudge workings. Further, the literature suggests that the nudges can be effective in many environments, in order to introduce and promote more ecological alternatives to consumers for 'unsustainable products' in general.

Our results showed that, without price tags, participants were significantly more inclined to opt for the organic rather than the vegetarian alternative when prices are absent. The overall preference for organic meat in the absence of price information may be exploited by leaving out price information in, for example, the meat segment altogether or to reduce its effect - for example, by providing a product's 'real' price when taking environmental factors into account ${ }^{4}$.

When nudges work in environments without price tags, vegetarian preference was a little (but not significantly) more pronounced, but participants were still most inclined to choose the organic option. The findings lead to the belief that opting for vegetarian meat is not primarily motivated by the price, whereas price does play a role in the choice of opting (or not opting) for organic meat. Further research is needed to validate these findings and find the consumers' main motivations for the exact product selection.

Conclusively, the working of the presented nudges is consistent with the literature, and this experiment confirms that, when implemented correctly, they are effective at nudging people. These findings may influence ecological consumer purchases and help work towards more sustainable consumer behavior in general.

\section{CONCLUSION}

This study aimed to answer how digital systems can apply nudges to guide customers of web supermarkets into buying more ecologically friendly meat products or alternatives. Using the experiment website version that includes both prices and nudges showed that this approach is an effective way to guide consumers into a more ecologically friendly direction. Both nudges seem capable of diverting meat purchases towards vegetarian options. Nudging is less effective when price information is not available, but in these situations our participants steered towards what they considered better (in terms of more sustainable, or more socially acceptable) choices.

The results confirmed that price does play a role in choosing between regular, organic and vegetarian alternatives, with some tendency to choose the cheapest option. However, the effects of the nudges were stronger. This would mean that - even though organic and vegetarian options are inherently more expensive supermarkets can still convince customers to buy them. Our results show the effectiveness of direct comparison and pro-active suggestions at the moment that the customer makes a choice. We hope that this study will inspire supermarkets and other stores to experiment with new ways to guide customers to more sustainable choices.

\section{REFERENCES}

[1] Ifeoma Adaji, Nafisul Kiron, and Julita Vassileva. 2020. Evaluating the Susceptibility of E-commerce Shoppers to Persuasive Strategies. A Game-Based Approach. In Persuasive Technology. Designing for Future Change, Sandra Burri Gram-Hansen, Tanja Svarre Jonasen, and Cees Midden (Eds.). Springer International Publishing, Cham, 58-72.

[2] Hilary Byerly, Andrew Balmford, Paul J Ferraro, Courtney Hammond Wagner, Elizabeth Palchak, Stephen Polasky, Taylor H Ricketts, Aaron J Schwartz, and Brendan Fisher. 2018. Nudging pro-environmental behavior: evidence and opportunities. Frontiers in Ecology and the Environment 16, 3 (2018), 159-168. https://doi.org/10.1002/fee.1777 arXiv:https://esajournals.onlinelibrary.wiley.com/doi/pdf/10.1002/fee.1777

[3] CBS; Eurostat. 2018. Nederland in Europese top 5 online winkelen. https://www. cbs.nl/nl-nl/nieuws/2018/38/nederland-in-europese-top-5-online-winkelen

[4] Victor Danciu et al. 2008. The organic products in the green marketing laboratory. Theorical and applied economics 1, 518 (2008), 11-20.

[5] Christophe Demarque, Laetitia Charalambides, Denis J. Hilton, and Laurent Waroquier. 2015. Nudging sustainable consumption: The use of descriptive norms to promote a minority behavior in a realistic online shopping environment.

${ }^{4}$ https://www.heise.de/newsticker/meldung/Discounter-Penny-weist-wahreVerkaufspreise-aus- 4884506.html 
Journal of Environmental Psychology 43 (2015), 166 - 174. https://doi.org/10. 1016/j.jenvp.2015.06.008

[6] Paul Dolan, Michael Hallsworth, David Halpern, Dominic King, Robert Metcalfe, and Ivo Vlaev. 2012. Influencing behaviour: The mindspace way. Fournal of Economic Psychology 33, 1 (2012), 264-277.

[7] Shane Frederick, Leonard Lee, and Ernest Baskin. 2014. The Limits of Attraction. Journal of Marketing Research 51, 4 (2014), 487-507. https://doi.org/10.1509/jmr. 12.0061 arXiv:https://doi.org/10.1509/jmr.12.0061

[8] Kerstin Gidlöf, Andrey Anikin, Martin Lingonblad, and Annika Wallin. 2017 Looking is buying. How visual attention and choice are affected by consumer preferences and properties of the supermarket shelf. Appetite 116 (2017), 29 - 38 https://doi.org/10.1016/j.appet.2017.04.020

[9] João Graça, Abílio Oliveira, and Maria Manuela Calheiros. 2015. Meat, beyond the plate. Data-driven hypotheses for understanding consumer willingness to adopt a more plant-based diet. Appetite 90 (2015), 80-90. https://doi.org/10.1016/ j.appet.2015.02.037

[10] Jody C Hoenink, Joreintje D Mackenbach, Wilma Waterlander, Jeroen Lakerveld, Nynke van der Laan, and Joline WJ Beulens. 2020. The effects of nudging and pricing on healthy food purchasing behavior in a virtual supermarket setting: a randomized experiment. International fournal of Behavioral Nutrition and Physical Activity 17, 1 (2020), 1-12.

[11] Eric J. Johnson, Suzanne B. Shu, Benedict G.C. Dellaert, Craig Fox, Daniel G. Goldstein, Gerald Häubl, Richard P. Larrick, John W. Payne, Ellen Peters, David Schkade, Brian Wansink, and Elke U. Weber. 2012. Beyond nudges: Tools of a choice architecture. Marketing Letters 23, 2 (2012), 487-504. https://doi.org/10 1007/s11002-012-9186-1

[12] Ron Kohavi and Roger Longbotham. 2017. Online Controlled Experiments and A/B Testing. Springer US, Boston, MA, 922-929. https://doi.org/10.1007/978-14899-7687-1_891

[13] Nielsen. 2020. 'Picnic' Shakes Things Up: The Rising E-Commerce Player is Driving Modern Trade and E-Com Sales in the Netherlands Nielsen. https://www.nielsen.com/nl/en/insights/article/2020/picnic-shakesthings-up-e-commerce-driving-trade-e-com-sales/

[14] NPD. 2018. Majority of Online Grocery Shoppers Still Shop at Brick-andMortar Grocers. https://www.npd.com/wps/portal/npd/us/news/press- releases/2018/us-consumers-take-an-omnichannel-approach-when-it-comesto-grocery-shopping/

[15] Alexandros Paramythis, Stephan Weibelzahl, and Judith Masthoff. 2010. Layered evaluation of interactive adaptive systems: Framework and formative methods. User Modeling and User-Adapted Interaction 20, 5 (2010), 383-453. https://doi. org/10.1007/s11257-010-9082-4

[16] Watson R.R. Preedy V.R. 2010. 5-Point Likert Scale BT. In Handbook of Disease Burdens and Quality of Life Measures, Victor R Preedy and Ronald R Watson (Eds.). Springer New York, New York, NY, 4288. https://doi.org/10.1007/978-0387-78665-0\{_\}6363

[17] Christoph Schneider, Markus Weinmann, and Jan vom Brocke. 2018. Digital Nudging: Guiding Online User Choices through Interface Design. Commun. ACM 61, 7 (2018), 67-73. https://doi.org/10.1145/3213765

[18] Intan Sherlin, Ferry Siswadhi, and Elex Sarmigi. 2020. Analysing the Decoy Effect on Online Product Purchasing Preference: An Experimental Study. In Proceedings of the 6th Annual International Conference on Management Research (AICMaR 2019). Atlantis Press, 125-130. https://doi.org/10.2991/aebmr.k.200331.027

[19] Herbert A. Simon. 1955. A BEHAVIORAL MODEL OF RATIONAL CHOICE By. The Quarterly fournal of Economics 69, 1 (1955), 99-118. https://www.jstor.org/ stable/1884852?origin=JSTOR-pdf

[20] Basu Prasad Subedi. 2016. Using Likert type data in social science research: Confusion, issues and challenges. International journal of contemporary applied sciences 3, 2 (2016), 36-49.

[21] Amos Tversky and Daniel Kahneman. 1974. Judgment under uncertainty: Heuristics and biases. science 185, 4157 (1974), 1124-1131.

[22] Amos Tversky and Daniel Kahneman. 1981. The framing of decisions and the psychology of choice. science 211, 4481 (1981), 453-458.

[23] Markus Weinmann, Christoph Schneider, and Jan vom Brocke. 2016. Digital Nudging. Business and Information Systems Engineering 58, 6 (2016), 433-436. https://doi.org/10.1007/s12599-016-0453-1

[24] Amy L. Wilson, Elizabeth Buckley, Jonathan D. Buckley, and Svetlana Bogomolova. 2016. Nudging healthier food and beverage choices through salience and priming. Evidence from a systematic review. Food Quality and Preference 51 (2016), 47-64. https://doi.org/10.1016/j.foodqual.2016.02.009 